\title{
What Teachers Think about Self-Regulated Learning: Investigating Teacher Beliefs and Teacher Behavior of Enhancing Students' Self-Regulation
}

\author{
Charlotte Dignath-van Ewijk ${ }^{1}$ and Greetje van der Werf ${ }^{2}$ \\ ${ }^{1}$ Department of Psychology, School of Social Sciences, University of Mannheim, A 5, 6, 68131 Mannheim, Germany \\ ${ }^{2}$ Institute for Educational Research (GION), Rijksuniversiteit Groningen, Grote Rozenstraat 3, 9712 TG Groningen, The Netherlands \\ Correspondence should be addressed to Charlotte Dignath-van Ewijk, cdignath@mail.uni-mannheim.de
}

Received 31 May 2012; Revised 16 August 2012; Accepted 20 August 2012

Academic Editor: Annemie Desoete

Copyright (C) 2012 C. Dignath-van Ewijk and G. van der Werf. This is an open access article distributed under the Creative Commons Attribution License, which permits unrestricted use, distribution, and reproduction in any medium, provided the original work is properly cited.

\begin{abstract}
In order to foster self-regulated learning (SRL), teachers should provide students with learning strategies, as well as with constructivist learning environments that allow them to self-regulate their learning. These two components complement each other. When investigating teachers' promotion of SRL, not only teacher behavior, but also teachers' beliefs as well as their knowledge about SRL are relevant aspects to consider. Therefore, this study seeks to examine teachers' knowledge and beliefs on promoting SRL, as well as their predictive value on teachers' promotion of SRL in the classroom. Forty-seven primary school teachers completed questionnaires on knowledge and beliefs towards both components of the promotion of SRL: strategy instruction and a constructivist learning environment. In addition, teachers had to answer open-ended questions on their understanding of SRL, as well as their implementation of SRL in their classroom. The results show that teachers are more positive towards constructivist than towards SRL (teacher beliefs), and most teachers mentioned characteristics of constructivist learning environments, while only few teachers addressed strategy instruction when being asked about their understanding of SRL (teacher knowledge). Moreover, teacher beliefs are the only predictor for teacher behavior. The results indicate how teacher education could support teachers to learn how to promote SRL effectively.
\end{abstract}

\section{Introduction}

Research on the promotion of self-regulated learning (SRL) has revealed that students can learn how to self-regulate their learning, but investigation of training them to do so has pointed out teachers producing weaker effects of training than researchers do (see, e.g., [1] for primary school and [2] for secondary school). Observational studies of teachers fostering students' SRL have shown that teachers give students the freedom of self-regulation, but do not prepare them to handle the new responsibilities (see, e.g., [3]). Although most teachers tend to use learner-activating teaching methods, in most cases they neglect teaching their students how to learn (see, e.g., [4]). However, providing students solely with autonomy but not with means to execute strategies has not been found to be beneficial for students (see for an overview
[5]). Both the instruction of metacognitive strategies-strategies on how to learn-as well as learning environments that require and enable self-regulation have been found to predict students' self-regulation [6].

According to Perry et al. [7], most teachers agree with the concept to support their students to become self-regulated learners; yet many of the teachers that they investigated reported to feel unsure about how to do that. Knowledge of whether teachers do not know how to enhance their students' self-regulation or whether (for unknown reasons) they refuse to, could indicate where teacher training would have to start and which points would have to be addressed. Kramarski and Michalsky [8] found that teachers' ability for SRL was associated with their pedagogical knowledge as well as with their beliefs on student-centered learning. Looking backwards, it would even enhance our understanding of the delineated 
problem by comparing the beliefs of teachers who are fostering SRL in their classroom to those who are not. As Tillema [9] found, teacher beliefs are filtering the learning process in a way that learning is supported only when training content and teacher beliefs correspond. Thus, both-teachers' prior knowledge as well as their beliefs_-seem to have an impact on teacher learning and might also influence teacher behavior.

The goal of the present study was to investigate the relationship between teachers' knowledge and beliefs on fostering self-regulation of learning among their students and their teaching behavior, while taking into regard strategy instruction. Equally important was the consideration in how far students were provided with a learning environment conducive to self-regulation. Since research on SRL is increasingly taking students into account as early as at primary school age [1], we focused on investigating primary school teachers' promotion of SRL.

1.1. Fostering Self-Regulated Learning. When searching the literature on SRL, it becomes obvious that a wide range of definitions exists varying among their focus on different aspects of the concept. The probably most-quoted definition of SRL [10], grounded on social-cognitive theory, stems from Schunk and Zimmerman [11]: SRL means the learners' "...self-generated thoughts, feelings, and actions which are systematically oriented toward attainment of their goals."

As the literature shows, teachers can support students to acquire self-regulation strategies [2, 12], using different elements of instruction that are not necessarily mutually excluding: on the one hand, teachers can model strategy use, or explicitly instruct strategies $[6,13-15]$; on the other hand, teachers can structure the learning situation in a way that students have the opportunity to discover strategic procedures themselves. S. G. Paris and A. H. Paris [14] refer to two well-established theories to provide examples for both direct as well as indirect ways to support SRL. To illustrate explicit strategy instruction, they draw on Brown et al. [16] who distinguish three levels of strategy instruction. On the lowest level of training, the so-called blind training, students are induced to use a strategy without providing them with any information about this strategy in order to foster a concurrent understanding about the significance of this activity. They are not explicitly told why to use a certain strategy, and in which situations this activity is appropriate. The students are induced to perform a certain activity without being explicitly informed that this activity is a learning strategy. Although this can enhance children's use of this activity, it is prone to fail in its adaption as a general tool by the student. The intermediate level includes the informed training. Students are both induced to apply a certain strategy but are also provided with some information about the significance of this strategy. This type of training should lead to an improved performance as well as keeping the activity up when a similar problem reoccurs. The self-control training, the highest level of instruction, combines the informed training with an explicit instruction of how to apply, monitor, check, and evaluate that strategy. This type of training facilitates the transfer of strategy application to appropriate settings in the most sustainable way [16]. This aspect plays an important role when looking at the promotion of SRL.

Another example for direct, although less explicit ways of supporting SRL can be derived from Collins et al. [17] model of Cognitive Apprenticeship, which assumes successful teaching to be based on several components of the learning environment: the content taught, the instructional methods, the sequencing of learning activities, and the sociology of learning [17]. This way of apprenticeship almost approaches or can overlap with explicit strategy instruction. In addition to this, teachers can design the learning environment in a way that it fosters students' self-regulation.

Self-regulation is a complex concept, including various features of the learner and his or her environment that have an impact on the learning process [18]. Therefore, the promotion of SRL is supposed to take place on two different levels: in addition to systematic strategy instruction, students need opportunities for exercising self-regulation. Therefore, features of the learning environment that foster the application of self-regulation strategies should also be acknowledged. Theorists on self-regulation describe SRL as an "inherently constructive and self-directed process" (e.g., [19]). In the same scope, Pressley et al. [15] describe successful strategy instruction in constructivist terms. The environment has to have features that allow active construction of knowledge, in order to be conducive to SRL.

When investigating teachers' beliefs on promoting SRL, both approaches thus have to be taken into account: teachers' beliefs on the instruction of self-regulation strategies, as well as their beliefs on the design of the learning environment. The same applies to teachers' knowledge on the promotion of SRL. In the following chapter, we will take a closer look at theories on teacher beliefs and teacher knowledge and will transfer these theories to teacher beliefs and knowledge about the promotion of SRL.

\subsection{Teacher Beliefs}

1.2.1. A Distinction between Teacher Beliefs and Teacher Knowledge. According to Pajares [20], when talking about teachers' attitudes towards education, one refers to teachers' edu-cational beliefs as only a subpart of teachers' general beliefs system. Beliefs encompass both attitudes and subjective norms, which makes it difficult to disentangle teachers' indi-vidual preferences from their opinion on how things have to be. Knowledge is based on objective facts, while beliefs are affective and involve a certain kind of judgment or eva-luation. Therefore, teachers can gain new knowledge, but are still influenced by their beliefs when deciding whether they accept it as true or not [21]. Although when examining teacher knowledge the focus is more on cognition, while beliefs include more emotional aspects, both concepts are intertwined and hard to fully separate during assessment [22].

Teacher knowledge can be classified into three categories: pedagogical knowledge, content knowledge, and pedagogical content knowledge [23]. Pedagogical knowledge implies 
teachers' knowledge about how to teach, while content knowledge refers to the subject matter that teachers have to teach. Pedagogical content knowledge-as opposed to general pedagogical knowledge-relates to teaching strategies on how teachers transfer a specific subject matter to their students, including knowledge on representing the subject matter to make it understandable for students, as well as knowing about students' conceptions and misconceptions. Teacher knowledge and beliefs on fostering self-regulated learning when looking at teacher beliefs on pedagogical practice, most studies distinguish between two dichotomous concepts: constructivist versus empiricist (also traditional) views on learning [24]. However, the question is whether both sides really have to be opposed to each other. When drawing on the theories on supporting students' self-regulation reported earlier in this paper, both conceptions can be beneficial (see [6]), probably in different moments a direct strategy instruction would probably go along with moments of more traditional teaching, while the creation of a constructivist learning environment would of course fit to the constructivist views on learning. Nevertheless, both are necessary and one cannot work without the other. Several studies researching teacher beliefs have already questioned a strict dichotomous distinction between both conceptions [24, 25]. Defining teacher beliefs on SRL reveals a complex construct involving several aspects of teacher beliefs. On the one hand, this includes how teachers think about learning in general: is learning regarded as a process of transmission of knowledge or is learning the process of constructing knowledge? General beliefs on pedagogical practice can cover this aspect. On the other hand, beliefs on fostering SRL also include beliefs on how to instruct and how to foster strategy use, which goes beyond general pedagogical beliefs, for example, in terms of beliefs on how many strategies to instruct at a time, or how to integrate the instruction of a certain strategy into the content of a lesson, as well as measures taken to support transfer of strategy use to other contexts.

The same applies to teacher knowledge. Do teachers know about the importance of providing students with strategies before or in addition to giving them autonomy while learning? How much do teachers know about one or both aspects of fostering SRL? Askell-Williams et al. [26] rank teachers' knowledge about scaffolding SRL among content knowledge and among pedagogical content knowledge about cognitive and metacognitive learning strategies. They report that beginning teachers lack a strong knowledge on how to learn [26].

1.2.2. Teacher Beliefs, Teacher Knowledge, and Teaching Behavior. In his review on beliefs, Pajares [20] sums up that beliefs strongly influence one's behavior. Belief structures more emotional and unstructured than knowledge, take over in complex or new situations, when appropriate reasoning is not working. Most reviewers on teacher beliefs and teacher knowledge conclude that teacher beliefs are stronger predictors for teacher behavior than teacher knowledge is [20, 27]. Similar knowledge of teachers can thus lead to different teaching behavior. One explanation is that learned knowledge is often not used in practical situations. Many studies have delivered empirical support for the association between teacher beliefs and teacher behavior (e.g., [28-30]). Hashweh [29], for example, found that teachers with constructivist beliefs opposed to traditional beliefs of teaching turned out to be more likely to help students to elaborate on their ideas and conceptions, which could indicate teachers supporting students in using cognitive strategies. However, other studies could not find evidence for such an association and the majority of studies have not been able to prove causality (e.g., [31]; see for a review [24]).

Beliefs are relatively resistant to change. Only when they prove unsatisfactory, which they only do when being challenged, individuals are motivated to replace their beliefs. The older beliefs are, the stronger they are and the more difficult they are to replace, even when they are based on incomplete or incorrect knowledge, and even when people are confronted with new (and correct) information. The perseverance of beliefs is not only due to their emotional quality, but also due to encoding biases that support confirmation of existing beliefs when integrating new information into the beliefs system. In the same way, perception is affected by beliefs, which in turn evokes behavior that is consistent with these beliefs-a self-fulfilling prophecy is at hand.

1.3. The Current Study. This study seeks to examine primary school teachers' knowledge on enhancing SRL, as well as their beliefs on the promotion of students' self-regulation. In addition, associations between teacher knowledge, teacher beliefs, and teacher behavior will be investigated. With regard to the presented models of fostering self-regulation, teachers' beliefs on the promotion of SRL were assessed including both beliefs on strategy instruction as well as beliefs on constructivist learning environments. We therefore used several scales as well as open-ended questions.

(1) Drawing on the results of observation studies investigating teachers' instruction to SRL (e.g., $[3,6]$ ), we also wanted to explore whether teachers report more positive views on constructivist learning environments or on the instruction of learning strategies (teacher beliefs) and whether teachers assign more importance to creating constructivist learning environments or to the instruction of learning strategies when thinking about fostering SRL (teacher knowledge).

(2) Moreover, we wanted to investigate whether teachers' implementation of SRL in their classroom is positively related with their beliefs as well as with their knowledge about the promotion of SRL. Furthermore, we would like to know whether teachers who perceive both the instruction of learning strategies and the design of the learning environment as important components of fostering SRL demonstrate the promotion of SRL.

\section{Method}

2.1. Sample. The questionnaire was sent to a randomized sample of 300 primary schools within the Netherlands. 
Forty-seven Dutch teachers who taught grade 7 or 8 (This corresponds to grade 5 and 6 in the US system.) filled in the questionnaire. Thirty-two teachers were female, fifteen teachers were male, which overrepresents the percentage of male teachers, as only $14.5 \%$ of Dutch primary school teachers are men. Teachers' age ranged from 24 to 63 years, covering all possible age groups of primary school teachers, with an average age of 40 years. Teachers' work experience ranged from 0.5 to 40 years with an average of 15 years work experience as primary school teacher. The sample might represent a group of teachers who seem to be interested in the topic of SRL, although we do not know whether all the teachers in the sample were highly motivated for SRL in general.

\subsection{Instruments}

2.2.1. Teacher Beliefs. In accordance with the model on fostering SRL presented earlier in this paper, the assessment of teachers' beliefs on the promotion of SRL includes both the instruction of self-regulation strategies (direct way of enhancing SRL), as well as the design of a SRL-conducive learning environment (indirect way of enhancing SRL). We therefore assessed teachers' attitude towards constructivist learning environments with the subscale ConstructiveOriented Beliefs about Learning and Instruction of the Beliefs about Primary Education Scale by Hermans et al. [32] that includes eight items. The constructive-oriented beliefs scale of the BPES was used to operationalize the indirect way of supporting SRL by creating a constructivist learning environment. Since we were not interested in traditional versus constructivist teacher orientation in general but only with the special focus of fostering SRL, the traditionaloriented beliefs scale of the BPES was not applied. For the constructivist learning environment (which is a rather general way of (also) fostering SRL (among others)), the items did not need to be adapted to the special context (since SRL is constructivist by nature); however, explicit strategy instruction is much more specific than what the traditionaloriented beliefs scale would assess, since in this case we wanted to assess teachers' orientation with regard to strategy instruction and not any instruction in general.

Moreover, we assessed teachers' preference for constructivist learning environments with three of the four verbal and graphic metaphors of the Teaching and Learning Perceptions Questionnaire by Kramarski and Michalsky [8]. The original Teaching and Learning Perceptions Questionnaire consisted of four metaphors (indirect way of enhancing SRL) that teachers had to rate. In this way, four perceptions of teaching and learning were assessed along a continuum from teacher-centered to student-centered: transmitting information ("The learner is like an empty vessel to be filled"), modeling by the teacher ("The learner is like a tourist on a guided tour"), and self-construction of knowledge ("The learner is like an independent mountain climber"). As we wanted to force teachers to make a choice for the metaphor that reflects best their perception on teaching and learning, we decided to use only the three of the metaphors that are most selective and to let teachers choose the metaphor that fitted best to them. With the scale of Hermans et al., we assessed in how far teachers favor a constructivist learning environment (so indirect way of fostering SRL). We also wanted to pinpoint whether teachers would prefer a totally indirect way of promoting SRL by teaching in a way that fits to the metaphor for self-construction of knowledge ("The learner is like an independent mountain climber"), or whether they prefer the direct way that fits to the metaphor for transmitting information ("The learner is like an empty vessel to be filled"), or whether they prefer the combination of both which fits to the metaphor for modeling by the teacher ("The learner is like a tourist on a guided tour").

Items to assess teacher beliefs on the instruction of SRL were adapted from the Self-Regulated Learning Teacher Belief Scale by Lombaerts et al. [33] covering 15 items (direct way of enhancing SRL). Examples of items can be found in Table 1.

All scales produced acceptable reliabilities: Cronbach's $\alpha$ was .67 for the subscale of the Beliefs about Primary Education Scale, and .75 for the Self-Regulated Learning Teacher Belief Scale. Therefore, the scales could be included into the analyses. Coding of the questions with open answer format was accomplished by two coders. Interrater reliabilities were found to range above $80 \%$.

2.2.2. Teacher Knowledge. Teachers' knowledge on the promotion of SRL was assessed partly in a quantitative and partly in a qualitative way. Eight items were generated to measure teachers' knowledge on effective strategy instruction (direct way of enhancing SRL) that were based on the model of effective strategy instruction by Pressley et al. [15], for example, "When instructing strategies, it is important to explain explicitly how to use a strategy and to mode strategy use." The reliability for the items on effective strategy instruction was $\alpha=.77$.

In addition to teachers' knowledge about strategy instruction, we wanted to capture whether teachers consider teaching self-regulation strategies at all. Therefore, teacher knowledge was also assessed in a qualitative way in order not to influence teachers with the direction of their response, no answer categories were provided but open-ended questions were asked like in an interview. First, teachers were asked to specify the best way to enhance students' learning behavior using the open question developed by Lonka et al. [35]: "What is the best way to enhance the learning behavior of students, to teach them learning to learn? Why?" "Learning to learn" was used as term as it also involves the concept of SRL (e.g., [36, 37]) but is more familiar to practitioners than the term "self-regulated learning". Second, to capture teachers' knowledge (conceptions and misconceptions) about SRL, teachers were questioned on how they define the concept "self-regulated learning". Teachers responded in writing, and all responses were transcribed and coded for data analysis using a coding scheme that had been developed to observe teachers' promotion of SRL in the classroom [6]. Both open-ended questions were analyzed by means of a coding scheme that built on the model of fostering SRL 
TABLe 1: Examples of items.

\begin{tabular}{|c|c|c|c|}
\hline Scale & Example item & $\begin{array}{l}\text { Measured } \\
\text { construct }\end{array}$ & $\begin{array}{l}\text { Way of } \\
\text { promoting SRL }\end{array}$ \\
\hline \multicolumn{4}{|l|}{ Teacher beliefs } \\
\hline Beliefs about Primary Education Scale: Hermans et al. [32] & $\begin{array}{l}\text { I find it important to use } \\
\text { time to have students } \\
\text { working together (in } \\
\text { groups) }\end{array}$ & $\begin{array}{l}\text { Teacher beliefs } \\
\text { on } \\
\text { constructivist } \\
\text { learning }\end{array}$ & Indirect \\
\hline $\begin{array}{l}\text { Teaching and Learning Perceptions Questionnaire: } \\
\text { Kramarski and Michalsky [8] }\end{array}$ & $\begin{array}{l}\text { The learner is like an } \\
\text { empty vessel that needs } \\
\text { to be filled }\end{array}$ & $\begin{array}{l}\text { Teacher beliefs } \\
\text { on student- } \\
\text { centered } \\
\text { learning }\end{array}$ & Indirect \\
\hline $\begin{array}{l}\text { SRLTB Self-Regulated Learning Teacher Belief scale: } \\
\text { Lombaerts et al. [34] }\end{array}$ & $\begin{array}{l}\text { The instruction of } \\
\text { learning strategies leads } \\
\text { to students being better } \\
\text { in evaluating their } \\
\text { learning }\end{array}$ & $\begin{array}{l}\text { Teacher beliefs } \\
\text { on } \\
\text { self-regulated } \\
\text { learning }\end{array}$ & Direct and indirect \\
\hline \multicolumn{4}{|l|}{ Teacher knowledge } \\
\hline Based on Pressley et al. [15] & $\begin{array}{l}\text { When instructing } \\
\text { strategies, it is important } \\
\text { to explain explicitly how } \\
\text { to use a strategy and to } \\
\text { mode strategy use }\end{array}$ & $\begin{array}{l}\text { Teacher } \\
\text { knowledge on } \\
\text { strategy } \\
\text { instruction }\end{array}$ & Direct \\
\hline \multirow[t]{2}{*}{ Lonka et al. [35] } & $\begin{array}{l}\text { What is the best way to } \\
\text { enhance the learning } \\
\text { behavior of students, to } \\
\text { teach them learning to } \\
\text { learn? Why? }\end{array}$ & $\begin{array}{l}\text { Teacher } \\
\text { knowledge on } \\
\text { learning to learn }\end{array}$ & Direct and indirect \\
\hline & $\begin{array}{l}\text { How would you define } \\
\text { "self-regulated } \\
\text { learning"? }\end{array}$ & $\begin{array}{l}\text { Teacher } \\
\text { knowledge on } \\
\text { self-regulated } \\
\text { learning }\end{array}$ & Direct and indirect \\
\hline
\end{tabular}

by both-direct strategy instruction and designing a constructivist learning environment. The direct instruction of learning strategies included all aspects of teacher behavior that serves to address the use of strategies, for example, teachers explaining the use of a certain strategy, reflecting with the students on their strategy use, discussing advantages and disadvantages of strategies, and modeling the use of a strategy by showing the students how to use it with or without thinking aloud. Both were coded-explicit discussion of strategy use, but also more implicit instruction of strategy use. Collins et al. [17] differentiate between four different aspects of apprenticeship that can serve to instruct strategies. Although these are rather indirect ways of instruction, they take place in a direct interaction between teacher and student(s): modelling, scaffolding, fading, and coaching. In modelling, the student watches the teacher at using a certain strategy. The student learns to use the strategy by observing the teacher using the strategy in terms of modelling. Scaffolding means the support that the teacher gives to the student in carrying out a task. This can imply that the teacher is doing parts of the task that the student cannot yet manage, but can also imply that the teacher just gives occasional hints to the student on what to do next. In fading, the teacher slowly removes his or her support and gives more and more responsibility to the student. Coaching comprises the whole process of apprenticeship instruction, including the choosing of tasks, providing students with hints, scaffolding, giving feedback, and structuring the procedures of the learning process. This way of apprenticeship almost approaches or can overlap with explicit strategy instruction. With regard to the design of a learning environment that allows students to selfregulate their learning, we coded teacher responses according to four common principles of constructivist learning, which are the basis of powerful learning environments [38], that were considered as being strongly related to the promotion of SRL: activating prior knowledge (relating new knowledge to already existing knowledge), cooperative learning (social interaction), learning in context, as well as self-regulated learning. Knowledge acquisition is defined as a process of knowledge construction, assuming that the learner builds his or her knowledge by relating new knowledge to already existing knowledge[39]. Second, different constructivist viewpoints also share the idea of the impact of social interaction during knowledge construction (e.g., [40]). As the level of communication among students is similar, but differs from the level of communication of the teacher, social interaction among the students should foster discussions on the subject matter that is related to deeper understanding [41]. Third, 
constructivist learning as learning in context should resemble real-life situations by challenging students with authentic and meaningful problem structures in terms of complex problems with interacting elements and allowing multiple solutions in order to facilitate transfer of knowledge (e.g., [42]). Fourth, constructivist learning implies students' selfdirection of their learning, based on the idea that it is insufficient to regulate one's cognitive activity when participating in active knowledge construction; but also metacognitive, affective, and behavioural aspects need to be regulated [11]. Students can benefit from learning environments that allow them to take over responsibility for their own learning [43]. In relation to that, constructivists agree on the importance of motivation to learn, affecting if, when and how students learn [44]. We coded whether teachers mentioned none, one or both of these two aspects. An example for a teacher response that was coded as strategy instruction was "Teaching your students to look at their work critically and to provide them with opportunities to check whether they did it the right way". Constructivist learning environment was coded for this exemplary teacher response: "Students can decide themselves in which order they want to work on their tasks and how much time they need for every task."

2.2.3. Teacher Behavior. Teachers had to explain what they do in order to enhance their students' self-regulation of learning in their classrooms. For the same reasons as mentioned for teacher knowledge, an open-ended question was asked to not direct teachers' answers. Again, this open-ended question was coded according to the model of fostering SRL directly through the instruction of learning strategies, as well as indirectly by creating a constructivist learning environment. A teacher response that was coded for strategy instruction was, for example, "I start every lesson by telling my students what the goal of the lesson will be." The example response "My students search for information themselves by asking each other questions in their group and try to solve problems together" was coded as promotion of a constructivist learning environment.

\section{Results}

3.1. Research Question 1: Teacher Beliefs and Teacher Knowledge on the Promotion of Self-Regulated Learning. With regard to our first research question, we wanted to know whether teachers assign more importance to the design of constructivist learning environments than to strategy instruction when asked about their beliefs and their knowledge on SRL.

3.1.1. Teacher Beliefs. Teachers' beliefs on SRL in primary school turned out to be relatively positive $(M=3.65, \mathrm{SD}=$ .41 on a five-point rating scale). Teachers' beliefs on constructivist learning were found to be very positive as well ( $M=4.04, \mathrm{SD}=.36$ on a five-point rating scale). However, most of the forty-five teachers who had answered the item on the metaphors representing views on teaching and learning were favoring the metaphor for "modeling by the teacher"
$(N=29)$ over "transferring information" $(N=8)$ or “"selfconstruction of knowledge" $(N=8)$; so not the most student-centered one but a moderate "average". Spearman correlations with the scale of these three metaphors and the scale of teacher beliefs on constructivist learning revealed that both measures were highly correlated (Rho $=.42^{* *}, P<$ .004). The more teachers agreed with constructivist views on teaching and learning, the more student-centered was the metaphor they chose for. A univariate analysis of variance was conducted to check for differences between the teachers who are favoring the three different metaphors. It turned out that teacher beliefs differ significantly between the three groups of teachers for both beliefs on $\operatorname{SRL}(F(2,42)=7.54$, $P<.01)$ as well as on constructivist learning $(F(2,42)=$ $4.88, P<.05)$. Post hoc analyses using the Scheffé post hoc criterion for significance indicated that the scale mean for teacher beliefs on SRL is significantly lower for teachers who chose the metaphors representing transmitting information $(M=3.58, \mathrm{SD}=.35)$ and modeling by the teacher $(M=3.54$, $\mathrm{SD}=.36)$ than for teachers who chose the metaphor representing self-construction of knowledge $(M=4.09, \mathrm{SD}=$ .38), $P<.05$. Concerning teacher beliefs on constructivist learning, the Scheffé test revealed significantly a higher-scale mean for teachers who had chosen for the metaphor "selfconstruction of knowledge" ( $M=4.33, \mathrm{SD}=.25)$ than for the metaphor "transmitting information" $(M=3.54, \mathrm{SD}=$ .36), $P<.05$. As a paired samples $t$-test revealed, teachers scored significantly higher on constructivist learning than on SRL $(t(46)=7.38, P<.01)$.

3.1.2. Teacher Knowledge. Pertaining to the instruction of strategies, teachers were very much in line with the characteristics of good strategy instruction proposed by Pressley and colleagues [15] which were assessed by means of the according items $(M=4.21, \mathrm{SD}=.39$ on a five-point rating scale). Concerning the questions on teachers' knowledge on the promotion of SRL that required open answers, responses were coded according to the options (a) direct strategy instruction, (b) indirectly fostering students' self-regulation through constructivist learning environments, or (c) direct and indirect strategy instruction. To the question "How would you define self-regulated learning", the responses of the forty teachers who had answered this question were coded into two categories: characteristics of learning that focused on student autonomy versus focus on learning strategy instruction. None of the forty teachers who had replied to the open-ended questions, had referred to both aspects, 31 teachers had described aspects of student autonomy (e.g., "students can choose themselves when they work on a task", or "students can learn according to their own speed and rhythm"), while nine teachers had emphasized aspects of strategy instruction (e.g., "students learn to know their strong points and how to use them", or "find strategies to improve learning"). With regard to the question "What is the best way to enhance the learning behavior of students, to teach them learning to learn? Why?", only two teachers did not give any answer. Again, the majority of 32 teachers stressed aspects of constructivist learning environments 
(e.g., cooperative learning, situated learning, student autonomy), but thirteen teachers responded with characteristics of strategy instruction (e.g., learning to plan one's learning process, reflecting together on how to learn, etc.) as well as constructivist learning environments. No teacher focused on the instruction of strategies only.

3.1.3. Teacher Behavior. When asked whether and how teachers incorporate aspects to foster SRL into their teaching, only seven teachers responded not to do so at all. Twenty-six of the thirty-eight teachers, who had answered that they promoted SRL, mentioned only characteristics to foster student autonomy (e.g., discovery learning, cooperative learning, student autonomy, etc.), while five teachers also reported to instruct learning strategies as well (e.g., "I'm teaching my students how to plan their learning"). Descriptives can be found in Table 2 .

\subsection{Research Question 2: Predicting Teacher Behavior with} Teacher Beliefs and Teacher Knowledge. Ordered logistic regressions were computed to analyze the predictive impact of teacher beliefs concerning constructivist learning environments, teacher beliefs concerning SRL, as well as teachers' knowledge concerning fostering SRL on their self-reported promotion of SRL in their classrooms. We chose ordered logistic regressions [45] since our dependent variable was coded according to three answering categories that reproduce ordered levels (no promotion of self-regulated learning/providing students with a constructivist learning environment only/additionally instructing learning strategies). According to our second research question, we wanted to investigate the predictive value of teacher beliefs and teacher knowledge to teacher behavior. As Table 3 shows, the analyses revealed that when controlling for all teacher beliefs and teacher knowledge variables only teachers' beliefs on SRL predicted teacher behavior $(B=2.52, P<.05)$. Teacher beliefs on constructivist learning and their perception of student versus teacher-centered teaching and learning did not predict teacher behavior significantly, neither did teachers' knowledge.

\section{Discussion}

4.1. Summary. In this study we investigated teacher beliefs and teacher knowledge on how to foster SRL and tested whether they predict teachers' promotion of SRL in their classrooms. As the results to the first research question show, teachers are more positive towards constructivist than towards SRL. This is in line with observation research on teachers' promotion of SRL, revealing teachers to mainly provide students with autonomy, but not to teach them learning strategies that help to deal with this autonomy (e.g., $[3,6])$.

When being asked how they would define self-regulated learning in order to assess teacher knowledge, most teachers mentioned characteristics of constructivist learning environments, while only few teachers addressed strategy instruction. No teacher reported to integrate both aspects of fostering SRL. Upon the second question to assess teacher knowledge (What is the best way to enhance the learning behavior of students, to teach them learning to learn?), again most teachers named characteristics of constructivist learning environments. However, thirteen teacher answers included both aspects the learning environment as well as strategy instruction. No teacher mentioned strategy instruction only. The results indicate that primary school teachers have already incorporated the idea of designing constructivist learning environments to foster students' self-regulation into their teaching conceptions. This result is in line with the result that arises from the analyses of teacher beliefs. Most teachers have a positive attitude towards constructivist as well as (slightly less positive) towards SRL at primary school, and most teachers associate SRL with student autonomy through constructivist learning environments. These results are not surprising, considering the results of classroom observation studies on the promotion of SRL that have produced a similar picture. Teachers do create learning environments that allow students to self-regulate; however, they do not provide students with the necessary learning strategies $[3,6]$. Yet, teachers differentiate between SRL and learning to learn, assigning more importance of the learning environment to the term "self-regulated learning", but integrating the aspect of strategy instruction into their definition when being asked for "learning to learn". Teachers refer more to the part of explicit strategy instruction when they think of "learning to learn", and they refer more to the indirect way of fostering SRL when they think of the term "self-regulated learning". Both concepts—self-regulated learning and learning to learn-seem to be rather independent concepts for most of the teachers. This is in line with a result that Waeytens et al. [46] found when interviewing teachers about their definition of "learning to learn". The concept is rather vague and unclear for many teachers.

When looking at teacher beliefs and teacher knowledge, it becomes clear that teachers have positive beliefs towards SRL, but they do not dispose of a broad knowledge on how to foster it. Most teachers do not cover both aspects of fostering their students' self-regulation. The same result occurs when looking at teachers' behavior. With regard to our first research question, we can conclude that both can be confirmed: The results of teacher beliefs and knowledge reflect earlier results on teacher behavior observed in their classrooms. However, the majority of teachers chose a metaphor representing the modeling of the teacher to reflect their perception of teaching and learning and not the most student-centered metaphor representing self-construction of knowledge. Thus, these teachers do acknowledge their task of modeling which plays an important role in strategy instruction (see [17]).

Concerning the predictive value of teacher beliefs, it turned out that only teacher beliefs on SRL predicted teachers fostering SRL in their classrooms, but not their beliefs on constructivist learning environments. Those teachers, who do integrate both aspects of the promotion of SRL into 
TABle 2: Descriptives.

\begin{tabular}{|c|c|c|c|c|}
\hline Scale & Reliability & Mean (SD) & Min & Max \\
\hline Hermans et al. [32]. Beliefs about Primary Education Scale & $\alpha=.67$ & $4.04(.36)$ & 3.30 & 4.70 \\
\hline Lombaerts et al. [34]. SRLTB Self-Regulated Learning Teacher Belief Scale & $\alpha=.75$ & $3.65(.41)$ & 2.75 & 4.88 \\
\hline Teacher Knowledge about Strategy Instruction: based on Pressley et al. [15] & $\alpha=.77$ & $4.21(.39)$ & 3.38 & 5.00 \\
\hline
\end{tabular}

TABLe 3: Multiple-ordered logistic regression to predict teacher behavior.

\begin{tabular}{|c|c|c|c|c|}
\hline Teacher behavior & $B$ & SE & $P$ & $e^{b}$ \\
\hline Teacher knowledge-1 & -.73 & .85 & .39 & .48 \\
\hline Teacher knowledge-2 & 1.30 & .91 & .16 & 3.66 \\
\hline Teacher beliefs on SRL & 2.52 & 1.15 & .03 & 12.45 \\
\hline Teacher beliefs on constructivism & -.94 & 1.38 & .50 & .39 \\
\hline Teacher beliefs on student versus teacher centeredness & .13 & .66 & .85 & 1.13 \\
\hline
\end{tabular}

their teaching, have particularly positive views on the concept. With regard to teacher knowledge, we found that teachers who covered both aspects in their answers also more frequently reported to integrate both aspects into their teaching. However, as the regressions showed, only teachers' beliefs on SRL predicted teacher behavior when including all variables into the analyses. This finding is consistent with Lombaerts et al. [34] who also found only teachers' beliefs on SRL to predict teachers' recognition of self-regulation practices.

An interesting point that requires further investigation is the inconsistency between teacher beliefs and teacher practice. Although teachers consider SRL as important, most of them do not integrate strategy instruction into their teaching. As teachers' beliefs seem so positive, there might be misconceptions among teachers about providing students with the tools to manage autonomy effectively. A limited or improper theoretical understanding of teachers could lead to frustration among students as well as among teachers about SRL (see [47]).

4.2. Limitations. The presented study is subject to some limitations. The small sample size does not allow generalization to primary school teachers at large. Teachers who were willing to participate were probably already motivated and interested in the topic. Thus, the general picture on teachers' beliefs on self-regulated and constructivist learning might be less positive and less promising. However, the results on teachers' knowledge-assuming that the teachers of this sample were more motivated and interested than the average teacher-allow the assumption that the knowledge of primary school teachers in general might be even more limited with regard to direct and indirect promotion of SRL. A second limitation is the assessment of teachers' beliefs, knowledge, and behavior by means of self-report. Teachers might want to produce a more positive picture so that their self-report could be subject to social desirability. Classroom observations could serve to get a more representative picture of teachers' behavior with regard to fostering students' selfregulation. Finally, a general difficulty in assessing teacher beliefs and knowledge is that both are hard to assess separately from each other, since the two constructs are hard to disentangle also from a theoretical perspective. Moreover, we have tried to cope with the risk of teachers answering in a socially desirable way by asking them open questions to assess their knowledge on fostering SRL. This goes along with the general disadvantage of open questions, that they cannot provide ratings.

4.3. Implications. The results of this study can give an indication to the causes why teachers do not instruct SRL more often, and where researchers and teacher educators would have to start in order to enable teachers to promote SRL effectively. When looking at teachers' conceptions of the enhancement of self-regulation among their students, it becomes clear that the area of direct strategy instruction has somehow got lost in teachers' minds (or has never existed) next to the constructivist idea of leaving students the autonomy to regulate their learning on their own. The results illustrate the need for informing teachers through teacher training. Concerning primary school teachers, the problem lies not in teachers' attitude but rather a lack of knowledge on how to support students' self-regulation effectively. However, teacher beliefs play the crucial role when predicting teachers' promotion of SRL in their classrooms. Helping teachers to develop an effective way of integrating SRL into their teaching would have to start by creating awareness of both ways to foster self-regulation. Moreover, the study has shown that teachers already dispose of positive attitudes towards the idea of providing students with autonomy. The question is whether the positive picture that has appeared in this study really constitutes the base that teacher educators would have to start from, or whether it reflects teachers' ideas on how they should think. When trying to change teachers' beliefs on enhancing SRL, there might be more variables affecting teacher behavior than just their conceptions on promoting 
it. One could think, for example, of teachers' self-efficacy. Teachers might appreciate the idea of SRL, but if they do not feel capable of managing more student autonomy, they won't integrate it into their teaching, no matter their positive beliefs. As Kramarski and Revach [47] concluded, based on the teacher training that they had conducted to help teachers' integrating SRL in their classrooms, teachers' self-efficacy might be related to teachers' professional development and might cause teachers not implementing what they have learned during training. Future research should account for teachers' perceived behavioral control when further investigating the association between teacher beliefs and teacher behavior with regard to fostering self-regulation.

Furthermore, with regard to teacher training, one should keep in mind that teacher beliefs also influence the perception of new information $[9,20]$. Therefore, it is crucial to be aware of teachers' conceptions and misconceptions and to take them into account when developing trainings. Moreover, training should take place as early as possible for two reasons. First, preservice teachers in the beginning of their career start using traditional teaching methods that they know from their own schooling experience (see [24]). Second, teachers at some point develop their own (potentially incorrect) beliefs on the promotion of self-regulation based on their teaching experience. These beliefs then start influencing their perceptions of new information. It is important to change teacher beliefs before this happens.

\section{Acknowledgments}

The authors are grateful to Ruben Hermans, Bracha Kramarski, and Koen Lombaerts for providing them with their assessment instruments. Moreover, they appreciate the advice of Marjolein Deunk, Annemieke Jacobsen, Anouk Bergstra, and Mechteld van Kuijk on item formulations of the Dutch questionnaire. Thanks to Reyn van Ewijk for his statistical advice. Finally, they wish to thank Wendel Verbree for helping with the data collection.

\section{References}

[1] C. Dignath, G. Buettner, and H.-P. Langfeldt, "How can primary school students learn self-regulated learning strategies most effectively? A meta-analysis on self-regulation training programmes," Educational Research Review, vol. 3, no. 2, pp. 101-129, 2008.

[2] C. Dignath and G. Büttner, "Components of fostering selfregulated learning among students. A meta-analysis on intervention studies at primary and secondary school level," Metacognition \& Learning, vol. 3, no. 3, pp. 231-264, 2008.

[3] S. Bolhuis and M. J. M. Voeten, "Toward self-directed learning in secondary schools: what do teachers do?" Teaching and Teacher Education, vol. 17, no. 7, pp. 837-855, 2001.

[4] A. de Kock, P. Sleegers, and M. J. M. Voeten, "New learning and choices of secondary school teachers when arranging learning environments," Teaching \& Teacher Education, vol. 21, no. 7, pp. 799-816, 2005.
[5] P. A. Kirschner, J. Sweller, and R. E. Clark, "Why minimal guidance during instruction does not work: an analysis of the failure of constructivist, discovery, problem-based, experiential, and inquiry-based teaching," Educational Psychologist, vol. 41, no. 2, pp. 75-86, 2006.

[6] C. Dignath-van Ewijk, O. Dickhäuser, and G. Büttner, "Investigating how teachers foster self-regulated learning by means of classroom observations," submitted to Journal of Cognitive Education and Psychology.

[7] N. E. Perry, L. Hutchinson, and C. Thauberger, "Talking about teaching self-regulated learning: scaffolding student teachers' development and use of practices that promote self-regulated learning," International Journal of Educational Research, vol. 47, no. 2, pp. 97-108, 2008.

[8] B. Kramarski and T. Michalsky, "Investigating preservice teachers' professional growth in self-regulated learning environments," Journal of Educational Psychology, vol. 101, no. 1, pp. 161-175, 2009.

[9] H. H. Tillema, "Changing the professional knowledge and beliefs of teachers: a training study," Learning \& Instruction, vol. 5, no. 4, pp. 291-318, 1995.

[10] M. Boekaerts, "Bringing about change in the classroom: strengths and weaknesses of the self-regulated learning approach-EARLI presidential address, 2001," Learning \& Instruction, vol. 12, no. 6, pp. 589-604, 2002.

[11] D. Schunk and B. J. Zimmerman, Self-regulation of learning and performance: issues and educational applications, Lawrence Erlbaum Associates, Hillsdale, NJ, USA, 1994.

[12] B. J. Zimmerman and D. H. Schunk, "Self-regulated learning and performace. An introduction and an overview," in Handbook of Self-Regulation of Learning and Performance, B. J. Zimmerman and D. H. Schunk, Eds., pp. 1-14, Routledge, New York, NY, USA, 2011.

[13] G. G. Duffy, S. Miller, S. Howerton, and J. B. Williams, "Comprehension instruction: merging two historically antithetical perspectives," in The Routledge International Handbook of English Language and Literacy Teaching, D. Wyse, R. Andrews, and J. Hoffman, Eds., pp. 58-73, Routledge, Florence, Ky, USA, 2010.

[14] S. G. Paris and A. H. Paris, "Classroom applications of research on self-regulated learning," Educational Psychologist, vol. 36, no. 2, pp. 89-101, 2001.

[15] M. Pressley, K. R. Harris, and M. B. Marks, "But good strategy instructors are constructivists!” Educational Psychology Review, vol. 4, pp. 3-31, 1992.

[16] A. Brown, J. C. Campione, and J. D. Day, "Learning to learn: on training students to learn from texts," Educational Researcher, vol. 10, no. 2, pp. 14-21, 1981.

[17] A. Collins, J. S. Brown, and A. Holum, "Cognitive apprenticeship: making thinking visible," American Educator, vol. 6, no. 11, pp. 38-46, 1991.

[18] B. J. Zimmerman, "A social cognitive view of self-regulated academic learning," Journal of Educational Psychology, vol. 81, no. 3, pp. 329-339, 1989.

[19] P. H. Winne, "Inherent details in self-regulated learning," Educational Psychologist, vol. 30, pp. 173-188, 1995.

[20] M. F. Pajares, "Teachers' beliefs and educational research: cleaning up a messy construct," Review of Educational Research, vol. 62, pp. 307-332, 1992.

[21] P. A. Ertmer, "Teacher pedagogical beliefs: the final frontier in our quest for technology integration?" Educational Technology Research and Development, vol. 53, no. 4, pp. 25-39, 2005. 
[22] A. Woolfolk Hoy, H. Davis, and S. J. Pape, "Teacher knowledge and beliefs," in Handbook of Educational Psychology, P. Alexander and P. Winne, Eds., pp. 715-738, Lawrence Erlbaum Associates, Mahwah, NJ, USA, 2006.

[23] L. S. Shulman, "Those who understand: knowledge growth in teaching," Educational Researcher, vol. 15, pp. 4-14, 1986.

[24] L. Maggioni and M. M. Parkinson, "The role of teacher epistemic cognition, epistemic beliefs, and calibration in instruction," Educational Psychology Review, vol. 20, no. 4, pp. 445-461, 2008.

[25] D. J. Stipek, K. B. Givvin, J. M. Salmon, and V. L. MacGyvers, "Teachers' beliefs and practices related to mathematics instruction," Teaching \& Teacher Education, vol. 17, no. 2, pp. 213-226, 2001.

[26] H. Askell-Williams, M. J. Lawson, and G. Skrzypiec, "Scaffolding cognitive and metacognitive strategy instruction in regular class lessons," Instructional Science, vol. 40, pp. 413-443, 2012.

[27] D. M. Kagan, "Implication of research on teacher belief," Educational Psychologist, vol. 27, pp. 65-90, 1992.

[28] Z. Fang, "A review of research on teacher beliefs and practices," Educational Research, vol. 38, no. 1, pp. 47-65, 1996.

[29] M. Z. Hashweh, "Effects of science teachers' epistemological beliefs in teaching," Journal of Research in Science Teaching, vol. 33, no. 1, pp. 47-63, 1996.

[30] F. C. Staub and E. Stern, “The nature of teachers' pedagogical content beliefs matters for students' achievement gains: quasiexperimental evidence from elementary mathematics," Journal of Educational Psychology, vol. 94, no. 2, pp. 344-355, 2002.

[31] C. Pauli, K. Reusser, and U. Grob, "Teaching for understanding and/or self-regulated learning? A video-based analysis of reform-oriented mathematics instruction in Switzerland," International Journal of Educational Research, vol. 46, no. 5, pp. 294-305, 2007.

[32] R. Hermans, J. Van Braak, and H. Van Keer, "Development of the beliefs about Primary Education Scale: distinguishing a developmental and transmissive dimension," Teaching \& Teacher Education, vol. 24, no. 1, pp. 127-139, 2008.

[33] K. Lombaerts, F. De Backer, N. Engels, J. Van Braak, and J. Athanasou, "Development of the self-regulated learning teacher belief scale," European Journal of Psychology of Education, vol. 24, no. 1, pp. 79-96, 2009.

[34] K. Lombaerts, N. Engels, and J. Van Braak, "Determinants of teachers' recognitions of self-regulated learning practices in elementary education," The Journal of Educational Research, vol. 102, no. 3, pp. 163-174, 2009.

[35] K. Lonka, E. Joram, and M. Bryson, "Conceptions of learning and knowledge: does training make a difference?" Contemporary Educational Psychology, vol. 21, no. 3, pp. 240-260, 1996.

[36] B. K. Hofer and S. L. Yu, "Teaching self-regulated learning through a "learning to learn" course," Teaching of Psychology, vol. 30, no. 1, pp. 30-33, 2003.

[37] P. H. Winne, "Experimenting to bootstrap self-regulated learning," Journal of Educational Psychology, vol. 89, no. 3, pp. 397-410, 1997.

[38] E. De Corte, L. Verschaffel, and C. Masui, “The CLIA-model: a framework for designing powerful learning environments for thinking and problem solving," European Journal of Psychology of Education, vol. 19, no. 4, pp. 365-384, 2004.

[39] D. J. Cunningham, "Beyond educational psychology: steps toward an educational semiotic," Educational Psychology Review, vol. 4, no. 2, pp. 165-194, 1992.
[40] J. Greeno, A. Collins, and L. Resnick, "Cognition and learning," in Handbook of Educational Psychology, D. Berliner and R. Calfee, Eds., pp. 15-46, Macmillan, New York, NY, USA, 1996.

[41] R. E. Slavin, "Research on cooperative learning and achievement: what we know, what we need to know," Contemporary Educational Psychology, vol. 21, no. 1, pp. 43-69, 1996.

[42] R. E. Mayer and M. C. Wittrock, "Problem-solving transfer," in Handbook of Educational Psychology, D. Berliner and R. Calfee, Eds., pp. 45-61, Macmillan, New York, NY, USA, 1996.

[43] G. Tenenbaum, S. Naidu, O. Jegede, and J. Austin, "Constructivist pedagogy in conventional on-campus and distance learning practice: an exploratory investigation," Learning and Instruction, vol. 11, no. 2, pp. 87-111, 2001.

[44] D. H. Schunk and B. J. Zimmerman, Self-Regulated Learning. From Teaching to Self-Reflective Practice, Guilford, New York, NY, USA, 1998.

[45] J. Hardin and J. Hilbe, Generalized Linear Models and Extensions, Stata Press, College Station, Tex, USA, 2007.

[46] K. Waeytens, W. Lens, and R. Vandenberghe, "Learning to learn': teachers' conceptions of their supporting role," Learning \& Instruction, vol. 12, no. 3, pp. 305-322, 2002.

[47] B. Kramarski and T. Revach, "The challenge of self-regulated learning in mathematics teachers' professional training," Educational Studies in Mathematics, vol. 72, pp. 379-399, 2009. 


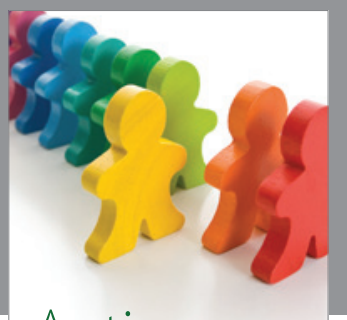

Autism

Research and Treatment
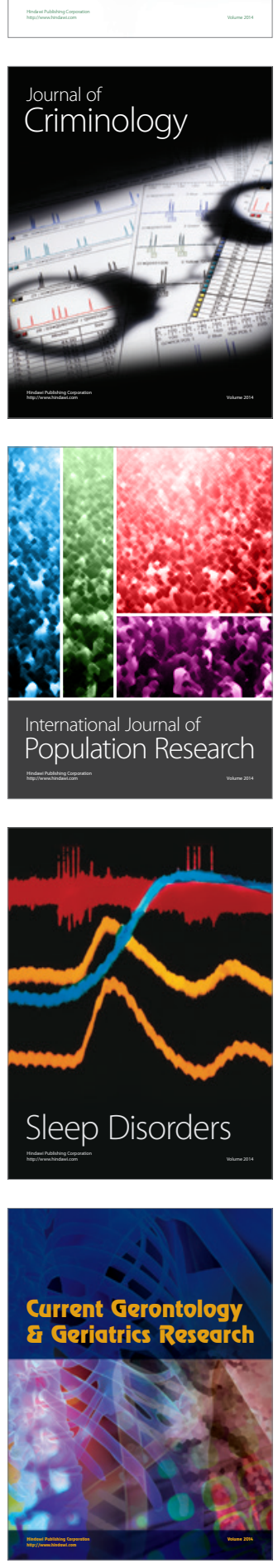
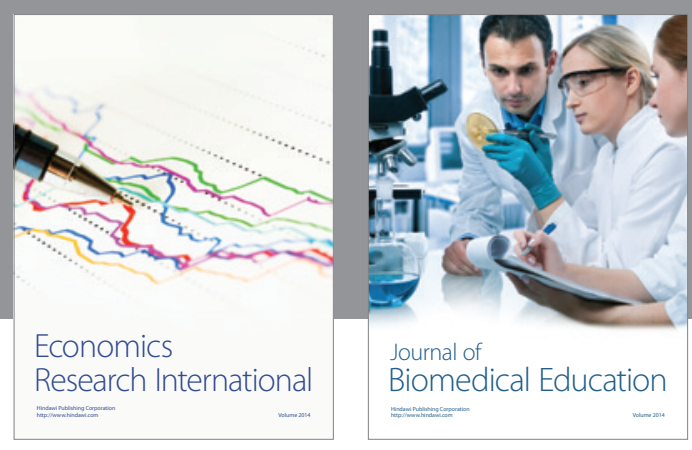

Journal of

Biomedical Education

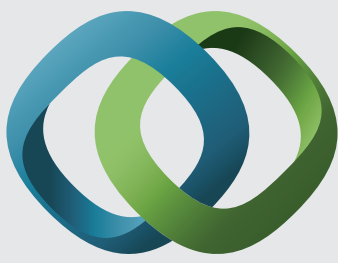

\section{Hindawi}

Submit your manuscripts at

http://www.hindawi.com
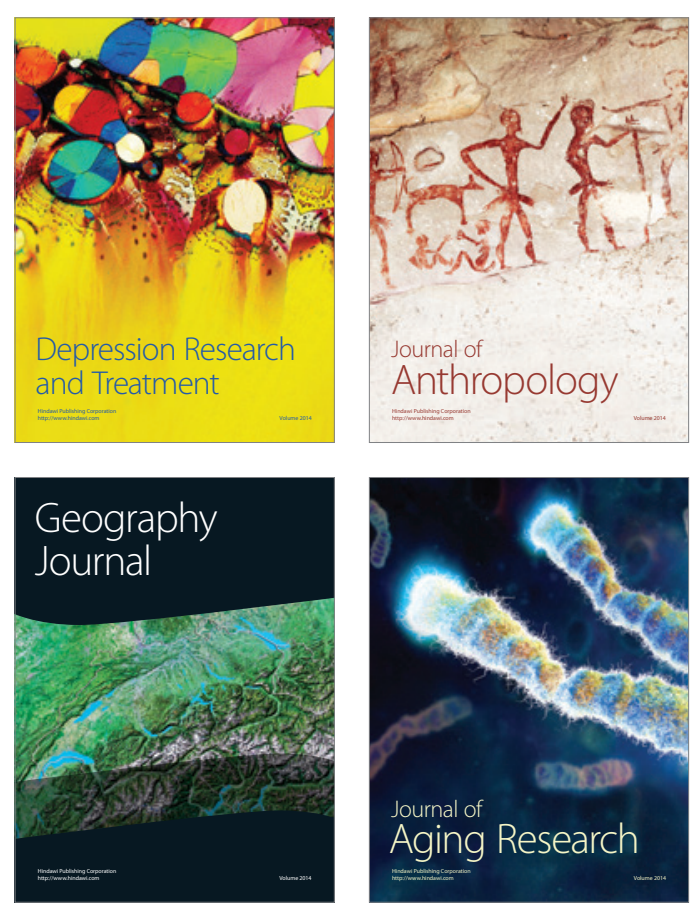

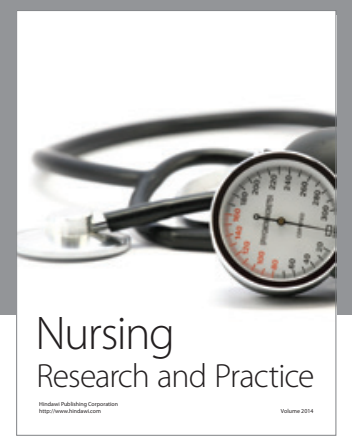

Nursing

Research and Practice

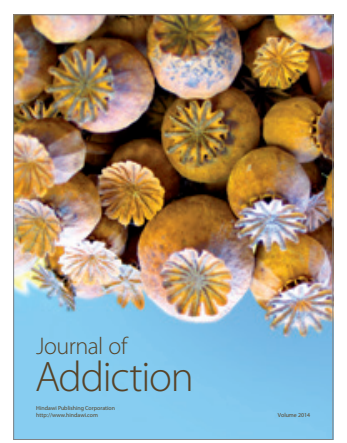

Child Development

Research

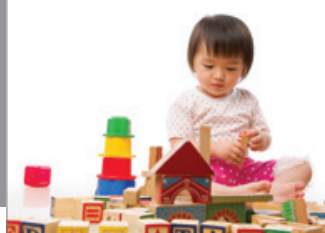

迥
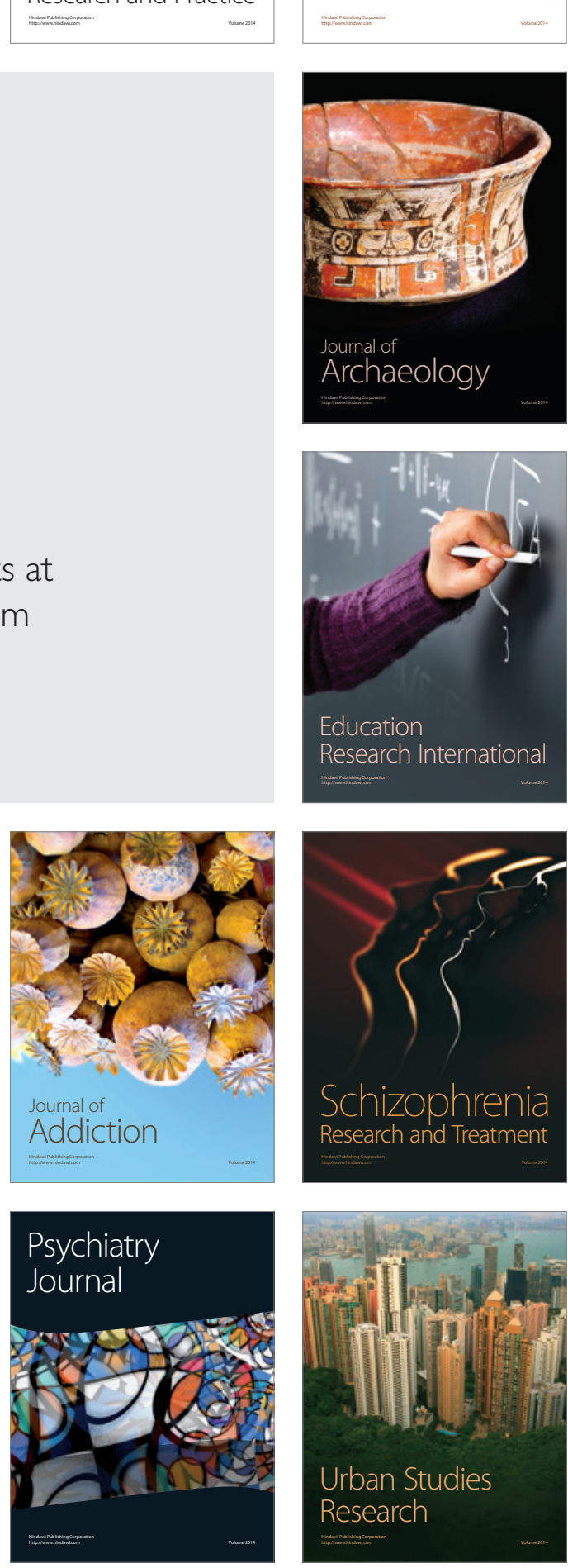